\title{
Microcephalic primordial dwarfism due to ZNF335 deficiency
}

INSERM

\section{Source}

INSERM. (1999). Orphanet: an online rare disease and orphan drug data base. Microcephalic primordial dwarfism due to ZNF335 deficiency. ORPHA:329228

Microcephalic primordial dwarfism due to ZNF335 deficiency is characterized by severe antenatal microencephaly, simplified gyration, agenesis of the corpus callosum, absence of basal ganglia (very rare), pontocerebellar atrophy and involvement of the white matter with secondary cerebral atrophy. Cong enital cataract, choanal atresia, multiple arthrogryposis and spastic tetraparesis can occur. 